\title{
REFORMA AGRÁRIA EM TERRAS PÚBLICAS
}

\author{
NILMA DE CASTRO ABE*
}

1. Introdução - 2. A reforma agrária na constituição e no estatuto da terra - 3. A reforma agrária em terras públicas - 4. Reflexões sobre o conceito de reforma agrária - 5. Conclusão - Bibliografia

\section{Introdução}

A Constituição Federal de 1988 estabelece que a destinação das terras públicas deve ser compatibilizada com a reforma agrária e a política agrícola ${ }^{1}{ }^{\text {impondo a }}$ utilização destas terras para fins de reforma agrária.

O contraste da nova ordem constitucional com a anterior concepção doutrinária do instituto da reforma agrária, construída sob a hipótese de incidir apenas sobre terras privadas, sugere a necessidade de revisão desta teoria para um resgate de sua coerência com a legislação em vigor.

Com o escopo de auxiliar nesta tarefa, o presente trabalho se propõe a identificar, em linhas gerais, os parâmetros oferecidos pelo nosso sistema jurídico para a promoção da reforma agrária em terras públicas e os instrumentos jurídicos aptos a implementá-la.

\section{A reforma agrária na constituição e no estatuto da terra}

A Lei 4.504/64 - Estatuto da Terra ofereceu o seguinte conceito de reforma agrária:

"Art. 1"...

$\S 1^{\circ}$. Considera-se Reforma Agrária o conjunto de medidas que visem a promover melhor distribuição da terra, mediante modificações no regime de sua posse e uso, a fim de atender aos princípios de justiça social e ao aumento da produtividade.

I C.F. Art. 188.

* Advogada no Estado do Pará

R. Dir. Adm.

Rio de Janeiro, 216: 65-74, abr./jun. 1999 
Art. 16. A Reforma Agrária visa a estabelecer um sistema de relações entre o homem, a propriedade rural e o uso da terra, capaz de promover a justiça social, o progresso e o bem-estar do trabalhador rural e o desenvolvimento econômico do País, com a gradual extinção do minifúndio e do latifúndio." (destacamos)

No sentido de delimitar seus principais elementos, façamos uma breve análise destas disposições.

Pela leitura do art. $1^{\varrho}, \S 1^{\varrho}$ verifica-se que a melhor distribuição de terras visa a eliminar a concentração fundiária - isto é, a existência de enormes extensões de terras nas mãos de poucos proprietários - para concretizar o princípio da justiça social. Esta redistribuição de terras também deve atender ao princípio do aumento da produtividade, ou seja, a terra deve ser redistribuída para quem queira torná-la produtiva, a fim de gerar um impacto positivo na economia brasileira.

Assim, a reforma agrária caracteriza-se pela redistribuição de terras para a promoção da justiça social (aspecto social) e do aumento da produtividade (aspecto econômico).

$\mathrm{O}$ art. 16, acima transcrito, reforça este entendimento, ao impor a gradual extinção do minifúndio e do latifúndio, conjugando objetivos sociais e econômicos.

Os dispositivos citados também sugerem que a Reforma Agrária volta-se precipuamente para incidir em terras privadas, pois se referem a uma "melhor distribuição", assim, uma "redistribuição" (art. $1^{0}, \S 1^{9}$ ) com a "gradual extinção do minifúndio e latifúndio" que, lembramos, só pode ser feita em imóveis de particulares (art. 16).

Todavia, outros dispositivos da Lei 4.504/64 sugerem a utilização de terras públicas para alcançar os mesmos fins da Reforma Agrária.

É o que se depreende, por exemplo, da leitura do seu art. $11, \S 1^{\circ}$, que impõe a utilização de terras devolutas na colonização a fim de erradicar os males do minifúndio ou do latifúndio. Além disso, o art. 17 do mesmo diploma legal fala em distribuição ou redistribuição de terras, sem precisar se são públicas ou privadas.

Percebe-se que o conceito de reforma agrária oferecido pelo Estatuto da Terra não delimitou de forma precisa o seu objeto (se incidente sobre terras públicas ou privadas), e apenas exemplificou os instrumentos jurídicos aplicáveis na execução das medidas de reforma agrária (desapropriação, regularização, venda, entre outras).

É portanto um conceito aberto, inclusive quanto aos próprios objetivos a serem perseguidos pela Reforma Agrária: a) a desconcentração de terra para redução das desigualdades sociais; b) o progresso sócio-econômico do trabalhador rural; e c) o desenvolvimento econômico nacional. Isso porque, ressalte-se com ênfase, a lei não impôs ao administrador público a implementação simultânea destes objetivos, permitindo o eventual entendimento de que apenas um deles possa ser perseguido sem o outro, e mesmo assim sua consecução ser designada como uma ação de reforma agrária.

Diante de tantas indefinições, a doutrina prevalecente buscou oferecer as necessárias complementações. Interpretou que a reforma agrária tem por objeto as terras privadas. e a sua implementação ocorreria por meio da desapropriação de terras utilizadas em desacordo à sua função social, seguida de uma distribuição das mesmas para um maior número de pessoas, buscando os já referidos objetivos de eliminar a 
concentração de terras, diminuir as desigualdades sociais e gerar o bem-estar do trabalhador rural.

Sustentou também que a redistribuição de terras privadas ociosas deveria ser o único alvo da reforma agrária, justificável pelo temor de que, com isso, se desviasse a atenção do grave problema de acumulação de terras privadas improdutivas, gerador de desigualdades sociais e impeditivo da efetiva modificação da estrutura agrária deficiente.

São em largo número os doutrinadores que defenderam este posicionamento. Vejamos alguns exemplos.

Fernando Pereira Sodero aponta o objeto e o principal instrumento da Reforma Agrária:

“Tendo sua expressão principal na modificação da estrutura fundiária, diz $a$ Reforma Agrária respeito aos bens imóveis rurais de particulares, que se situam no território nacional. Reforma Agrária não se faz em terras públicas, em terras de domínio público, sejam estas federais, estaduais e municipais." 2 (o grifo é nosso)

(...)

“A desapropriação por interesse social é o principal instrumento de Reforma Agrária (art. 17. do E.T), e tanto pode recair em minifúndio - para reagrupamento em caráter econômico - como em latifúndio - parcelamento em unidades familiares com bases cooperativistas." 3 (o grifo é nosso)

Em similar abordagem, Pinto Ferreira ${ }^{4}$ aponta o objeto e os objetivos da Reforma Agrária:

"...a reforma agrária é a mudança dos traços essenciais e totais da atual estrutura agrária em um sistema de distribuição, utilização e exploração da propriedade privada agrícola, tendente a liberar a massa campesina de sua servidão econômica e cultural" (o grifo é nosso)

Também Raymundo Laranjeira ${ }^{5}$ posiciona-se quanto aos objetivos da Reforma Agrária:

"Mas também sabemos, principalmente à vista da situação dos países subdesenvolvidos, como o nosso, que a reforma agrária merece ter por fundamento, como medida inicial, a própria modificação das dimensões dos imóveis, com a mudança dos direitos a eles pertinentes." (o grifo é nosso)

Segundo este entendimento, a reforma agrária teria como eixo central a desapropriação dos imóveis rurais - autorizada pelo não atendimento da função social da propriedade - para ulterior redistribuição de terras com o fim de realizar a justiça social e o bem-estar dos trabalhadores rurais.

2 SODERO, Fernando Pereira. Direito Agrário e Reforma Agrária. Ediçāo da Livraria Legislação Brasileira, São Paulo, 1968. p. 224.

3 SODERO, Fernando Pereira. Op. Cit. p.93.

4 FERrEIRA, Pinto apud LIMA, Rafael Augusto de Mendonça. Direito Agrário. Rio de Janeiro: Renovar, 1997. p. 233.

5 LARANJEIRA, Raymundo. Colonização e Reforma Agrária no Brasil. Rio de Janeiro: Civilização Brasileira, 1983. p.89. 
Resulta que a idéia de uma reforma agrária em terras públicas foi repelida ou considerada dispensável, um instrumento meramente paliativo das distorções fundiárias. Consequientemente, este tema foi pouco abordado e explorado pela doutrina.

Porém, as inovações introduzidas pela Constituição Federal de 1988 repercutem com relevância no instituto da reforma agrária, e solucionam vários impasses que possam emergir de uma leitura isolada do Estatuto da Terra.

Como exemplo, aponte-se que a localização do instituto da reforma agrária no Título da Ordem Econômica autoriza a afirmação de que o aumento da produtividade para viabilizar o desenvolvimento econômico nacional, um dos objetivos da reforma agrária $^{6}$, deve compatibilizar-se com os princípios da justiça social e dignidade da pessoa humana ${ }^{7}$, não podendo ser perseguido individualmente.

Outro, de essencial importância para as conclusões deste trabalho, é o de que a Constituição, ao ordenar a compatibilização da destinação das terras públicas com a reforma agrária e política agrícola ${ }^{8}$, tornou necessária a ampliação do conceito de reforma agrária tradicionalmente utilizado pela doutrina.

$O$ entendimento de que a reforma agrária limita-se às terras de particulares contraditaria o texto constitucional, o qual, inclusive, autoriza para tais fins a alienação ou concessão de terras públicas de área superior a dois mil e quinhentos hectares independentemente de prévia aprovação do Congresso Nacional ${ }^{9}$, reforçando a intenção do constituinte de assegurar esta destinação, reafirmada no âmbito da legislação ordinária nos termos do art. 13 da Lei 8.629/93. ${ }^{10}$

A Constituição Federal e a legislação ordinária tornam cogente a destinação preferencial das terras públicas para a implementação da reforma agrária, evidenciando a necessidade de identificação dos elementos que coordenam a reforma agrária em terras públicas e dos mecanismos jurídicos aptos a implementá-la.

\section{A reforma agrária em terras públicas}

Inicialmente, pode-se afirmar que a reforma agrária em terras públicas também tem como objetivos a justiça social e o desenvolvimento econômico nacional.

Porém, lembremos que o conceito anterior de reforma agrária foi construído pela doutrina a partir de dois pontos centrais: a desapropriação por descumprimento do princípio da função social da propriedade, e a redistribuição de terras.

Ora, tal conceito é inadequado para a discussão da reforma agrária em terras públicas, pois passa ao largo de seus problemas centrais, uma vez que a desapro-

\footnotetext{
6 Lei 4.504/64, art. 16.

7 GRAU, Eros Roberto. A Ordem Econômica na Constituição Federal de 1988. São Paulo: Malheiros, 1997. p. 245

8 C.F. Art. 188, caput.

9 C.F. Art. 188. $\$ 2^{\circ}$

10 Lei 8.629/93. art.13. “As terras rurais de domínio da União, dos Estados e dos Municípios ficam destinadas, preferencialmente. à execução de planos de reforma agrária."
} 
priação por descumprimento da função social da propriedade atinge principalmente o domínio de imóveis privados.

Melhor sorte ocorre com a possibilidade da distribuição ser um traço característico da Reforma Agrária em terras públicas. Mas, para uma melhor abordagem desta questão convém antes compreender os termos 'distribuição' e 'terras públicas'.

O termo distribuição não tem significado jurídico preciso. " A Lei 4.504/64 usa o termo no sentido de alienação, ${ }^{12}$ ou seja, transferência definitiva de domínio, porém a Constituição Federal de $1988^{13}$ fala em distribuição de imóveis rurais pela reforma agrária através de título de domínio ou concessão de uso.

Para evitar ambigüidades, entendemos ser de bom alvitre adotar o sentido já tradicional no direito brasileiro, ou seja, distribuir é transferir o domínio para outrem.

O termo "terras públicas" utilizado no art. 188 da Constituição engloba uma série de subcategorias jurídicas, fazendo-se necessária a sua pronta definição.

Entende-se que o termo terras públicas é sinônimo de "imóvel rural de propriedade pública”, ou seja, é o prédio rústico de área contínua que, independentemente de sua localização, se destine ou possa se destinar à exploração agrícola, pecuária, extrativa vegetal, florestal ou agroindustrial, ${ }^{14}$ e seja de propriedade do Estado.

Neste sentido, a denominação terras públicas engloba os seguintes tipos legais: as terras próprias, as terras devolutas, os terrenos de marinha e seus acrescidos, os terrenos marginais, as terras na faixa de fronteira, as terras indígenas e as ilhas. ${ }^{15}$

A diversidade de tipos envolvidos pela denominação de terras públicas impõe o estudo do regime jurídico de cada uma, de modo a identificar como pode ser efetivada a sua destinação pelo Poder Público.

Uma análise inicial já indica que nem todas as terras públicas são passíveis de distribuição, existindo terras públicas distribuiveis e as não distribuiveis.

Por exemplo, as terras próprias da União podem ser vendidas ou doadas, o que não se aplica aos terrenos de marinha. ${ }^{16}$

Assim, verifica-se que a distribuição é apenas um dos traços característicos da Reforma Agrária em terras públicas, a qual constitui um conjunto de medidas que envolvem a distribuição e a cessão da posse da terra para o particular, com o objetivo de realizar-se a justiça social e o desenvolvimento econômico nacional.

A sua implementação demanda institutos jurídicos que a viabilizem em todas as categorias de terras públicas, para que o princípio constitucional da destinação preferencial para fins de reforma agrária alcance a sua máxima efetividade.

A reforma agrária em terras públicas distribuíveis, ou seja, alienáveis, poderá ser implementada por meio de instrumentos que transfiram a propriedade ao parti-

11 SILVA, de Plácido. Vocabulário Juridico. 10 ed. Rio de Janeiro: Forense, 1987. Vol. I A-C. p.106.

12 Lei $4.504 / 64$, arts. 24, 25 e 26.

13 C.F. Art. 189, caput.

14 Lei 8.629/93, art. $4^{2}$.

15 Este entendimento depreende-se dos arts. 20 e 26 da Constituição Federal, os quais elencam, respectivamente, os bens públicos da União e do Estado, e também do art. $9^{0}$ da Lei 4.504/64, o qual fornece uma classificaçāo de terras públicas.

16 Lei $4.504 / 64$, art. 26. 
cular, para que este torne a terra produtiva, e satisfaça suas necessidades básicas de moradia, sustento e bem-estar.

Em terras públicas não distribuíveis o desafio é identificar institutos jurídicos aptos a conceder o uso e gozo dos imóveis públicos para o particular, com iguais objetivos.

Diante da ausência de institutos jurídicos adequados, o Estado só pode utilizar-se dos meios já disponíveis no ordenamento jurídico, tais como: concessão de uso, ${ }^{17}$ concessão de direito real de uso, ${ }^{18}$ aforamento, ${ }^{19}$ arrendamento, ${ }^{20}$ cessão de uso, ${ }^{21}$ venda, ${ }^{22}$ doação, ${ }^{23}$ legitimação de posse, ${ }^{24}$ e regularização de posse, ${ }^{25}$ para citarmos os principais.

Quanto a isto, porém, façamos duas ressalvas.

Primeiro, estes institutos não se aplicam a todas as categorias de terras públicas. Eles demandam uma compatibilização que varia segundo o disposto na legislação ordinária.

E depois, tais institutos não são de per si agrários, ou seja, não têm como fundamento a obrigatoriedade da realização da atividade agrária, de forma que se torna necessária uma adequação de tais institutos quando aplicados para fins de reforma agrária.

De fato, apenas a legitimação ${ }^{26}$ e a regularização de posse ${ }^{27}$ são autênticos institutos de direito agrário, uma vez que detêm os traços típicos da cultura efetiva e morada habitual. Os demais são institutos jurídicos de Direito Administrativo, voltados para a gestão de imóveis públicos pelo Estado.

Quando o administrador lança mão de tais institutos, sua atuação rege-se, normalmente, pelos princípios jurídicos administrativos. Todavia, na implementação de um plano de reforma agrária, a sua conduta deve pautar-se principalmente pelos princípios de Direito Agrário.

Queremos dizer com isto que sua ação deve atender aos parâmetros traçados pelos princípios jus-agraristas orientadores da reforma agrária, dentre os quais destacamos:

a) O princípio da distribuição: é traço característico da reforma agrária no Brasil e princípio norteador de um plano de reforma agrária. ${ }^{28}$ No que diz respeito às terras públicas, só é aplicável em algumas categorias, segundo prévia autorização legal.

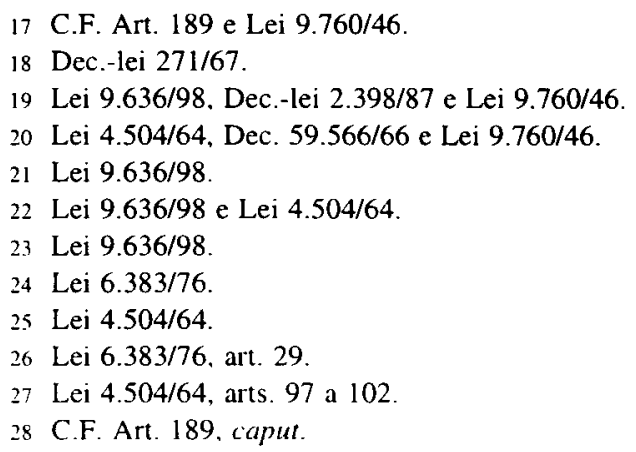


b) O princípio da produtividade da terra: um dos princípios do Direito Agrário previsto no Estatuto da Terra ${ }^{29}$ e na Lei $6.383 / 76 .{ }^{30}$ Encontra fundamento constitucional no princípio da função social da propriedade. ${ }^{31}$

c) O princípio da compatibilização da reforma agrária com a política agrícola: todo ato de reforma agrária traz no seu bojo um ato de política agrícola, a qual se traduz num conjunto de medidas econômicas, fiscais e sociais que visam a favorecer a fixação do homem no campo, pois ambas estão irremediavelmente interligadas. ${ }^{32}$

Embora a Constituição Federal tenha previsto no Capítulo III do Título VII "Da Política Agrícola e Fundiária e Da Reforma Agrária", bastaria mencionar "Da Política Agrária", sendo esta uma denominação mais adequada, por abranger as políticas agrícola, pecuária, fundiária, de desenvolvimento rural e de reforma agrária. $^{33}$

d) O princípio da valorização do trabalho humano: diretamente relacionado com o princípio da produtividade, pois é o trabalho humano que torna a terra produtiva. Constitui fundamento da Ordem Econômica Constitucional, dentro da qual se insere a reforma agrária, e também integra o princípio da função social da propriedade. $^{34}$

e) O princípio da morada habitual: a terra representa para o rurícola não apenas meio de produção, mas também o seu lar, suprindo-lhe a necessidade de moradia. Encontra fundamento legal na Constituição Federal ${ }^{35}$ e também na Lei 6.838/76. ${ }^{36}$

f) O princípio da justiça social: integra o conceito de reforma agrária previsto no Estatuto da Terra, constitui um dos princípios basilares do Direito Agrário e fundamento da ordem econômica constitucional ${ }^{37}$ da qual a política agrária faz parte.

Entende-se por justiça social a redução das desigualdades entre as classes sociais, que se desenvolve basicamente pelo acesso de todos aos bens vitais, os quais satisfazem as necessidades essenciais do ser humano, permitindo a sua existência digna. Enquanto objetivo a ser concretizado pelo instituto da reforma agrária, traduz a eliminação da concentração fundiária, o amplo acesso à terra, redução das desigualdades sociais, o bem-estar e progresso do trabalhador rural.

A reforma agrária constitui, sem dúvida, um dos institutos jurídicos viabilizadores da justiça social, porque promove a redistribuição de riquezas, e permite a construção de uma real democracia ${ }^{38}$ na medida em que propicia a ampla participação de todos nos rendimentos da produção.

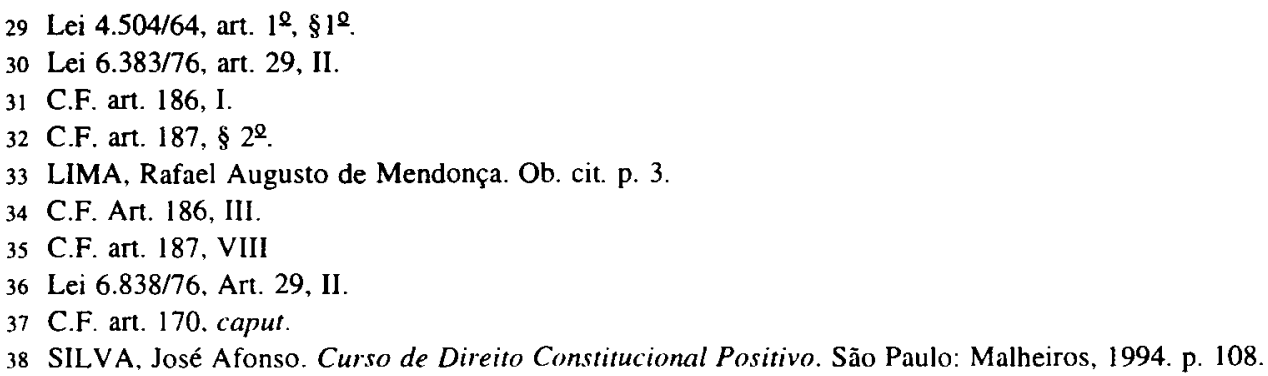


g) O princípio da redução das desigualdades sociais e regionais: relacionado com o princípio da justiça social. Traduz também um dos princípios da ordem econômica constitucional ${ }^{39}$ da qual a política agrária faz parte.

Reafirma um dos objetivos fundamentais da República Federativa do Brasil previsto no art. $3^{0}$, III da Constituição Federal. ${ }^{40}$ Embora este princípio seja um dos fundamentos do Estado Brasileiro, e portanto, de toda a ordem jurídica nacional, no âmbito do Direito Agrário ele ganha significado especial, moldando o instituto jurídico da reforma agrária e reproduzindo a sua eficácia.

Erradicar a pobreza e a marginalização significa viabilizar o acesso de todos aos bens vitais, aos bens que permitam a existência com dignidade, integrando-os ao processo produtivo, e evitando que permaneçam milhares de brasileiros às margens do desenvolvimento.

Reduzir as desigualdades sociais significa redistribuir a renda e a riqueza de forma que não exista um verdadeiro abismo entre as classes sociais.

Reduzir as desigualdades regionais significa implementar um desenvolvimento nacional unificado, sem que haja o progresso de uma região em detrimento de outra.

h) O princípio da utilização adequada dos recursos naturais e preservação do meio ambiente: encontra fundamento constitucional no art. $225, \S 1^{9}$, V, e na Lei $8.171 / 911^{41}$

Um plano de reforma agrária em terras públicas envolve medidas de preservação do meio ambiente, para impedir a exaustão do potencial produtivo da terra e os danos aos ecossistemas existentes.

Relaciona-se com o princípio da produtividade, uma vez que o desenvolvimento econômico, para atender à lei, precisa ser ecologicamente sustentável, revelando o aspecto regional da reforma agrária, que só será bem-sucedida se levar em conta o potencial produtivo da região e os diversos ecossistemas existentes.

É a obediência a estes princípios que diferenciará a ação do Estado na promoção da reforma agrária em terras públicas, ampliando-a para além da mera atividade de gestão de imóveis públicos.

\section{Reflexões sobre o conceito de reforma agrária}

A diversidade acima apontada autoriza um enfoque que estude a reforma agrária em dois planos: a reforma agrária em terras privadas e a reforma agrária em terras públicas.

A reforma agrária em terras privadas tem como eixo central a identificação do exercício irregular do direito de propriedade privada, e a sua acumulação ilícita. Corresponde a uma atuação do Estado para redistribuir terras, a fim de eliminar a

39 C.F. art. 170, VII.

40 "C.F. art. 30. Ill -- erradicar a pobreza e a marginalização e reduzir as desigualdades sociais e regionais."

41 Lei 8.171/91, art. 19, parágrafo único. 
concentração fundiária, viabilizar o bem-estar do trabalhador rural e desenvolver a economia nacional.

Sua importância está na concretização do objetivo da desconcentração fundiária, especialmente relevante para o Brasil, num momento em que a sociedade brasileira sofre e convive com as consequiências de graves distorções sociais, geradas entre outros motivos, pela imensa concentração de terras nas mãos de poucos proprietários.

A reforma agrária em terras públicas envolve especificamente uma discussão sobre a destinação de glebas públicas segundo uma ordem de prioridade prevista em lei. Corresponde a uma atuação do Estado para distribuir terras ou transferir a sua posse para o particular, visando alcançar o bem-estar do trabalhador rural e o desenvolvimento da economia.

Em suma, constata-se que o conceito de reforma agrária anteriormente utilizado pela doutrina merece ampliação, para que também abranja a utilização de terras públicas.

\section{Conclusão}

As inovações introduzidas pela Constituição Federal de 1988 concederam uma nova feição ao instituto da reforma agrária, exigindo uma reconstrução doutrinária da exatidão do seu conceito, a fim de torná-lo compatível com a ordem jurídica vigente.

A localização do instituto da reforma agrária sob o título da Ordem Econômica, acarreta a interpretação de que o aumento da produtividade para viabilizar o desenvolvimento econômico nacional, ${ }^{42}$ um dos objetivos da reforma agrária, deve compatibilizar-se com os princípios da justiça social e dignidade da pessoa humana, ${ }^{43}$ não podendo ser perseguido isoladamente, lançando ao ilícito as políticas do poder público que assim procederem.

A previsão constitucional do princípio da destinação das terras públicas para fins de reforma agrária ampliou obrigatoriamente o objeto deste instituto, e conseqüentemente, os mecanismos jurídicos adequados a implementá-la, abrangendo também os institutos administrativos de gestão de bens públicos necessários para a concretização de tais objetivos.

Ao lançar mão de tais instrumentos jurídicos, o Poder Público deve atender aos princípios de Direito Agrário existentes no ordenamento jurídico, atualizados pelos ditames de nossa Constituição Federal em vigor.

\section{Bibliografia}

GRAU, Eros Roberto. A Ordem Econômica na Constituição de 1988. 3 ed. São Paulo: Malheiros, 1997. 
LARANJEIRA. Raymundo. Colonização e Reforma Agrária no Brasil. Rio de Janeiro: Civilização Brasileira, 1983.

LIMA, Rafael Augusto de Mendonça. Direito Agrário. Rio de Janeiro: Renovar, 1994.

SILVA, de Plácido. Vocabulário Jurídico. 10 ed. Rio de Janeiro: Forense, 1987. Vol I A-C.

SILVA, José Afonso da. Curso de Direito Constitucional Positivo. 9 ed. São Paulo: Malheiros, 1994.

SODERO, Fernando Pereira. Direito Agrário e Reforma Agrária. Edição Livraria Legislação Brasileira, São Paulo, 1968. 